\title{
Polyamine Alterations in Isolated Zucchini Cotyledons Grown in Presence of Cytokinins and $\mathrm{Cu}^{2+}$
}

\author{
Maya Damyanova, Dessislava Todorova*, Iskren Sergiev \\ Institute of Plant Physiology and Genetics, Bulgarian Academy of Sciences, Sofia, Bulgaria \\ Email: ${ }^{*}$ dessita@bio21.bas.bg
}

Received 2 May 2014; revised 1 June 2014; accepted 21 June 2014

Copyright (C) 2014 by authors and Scientific Research Publishing Inc.

This work is licensed under the Creative Commons Attribution International License (CC BY). http://creativecommons.org/licenses/by/4.0/

c) (i) Open Access

\begin{abstract}
Polyamines are small nitrogen-containing organic molecules, which are widely distributed in plants. They are involved in the regulation of normal plant growth and developmental processes. In this study we examined the role of polyamines on the growth of Cucurbita pepo L. (zucchini) cotyledons incubated on solutions of different types of cytokinins (BA- $\mathrm{N}^{6}$-benzylaminopurine or 4PU-30- $\mathrm{N}^{1}$-(2-chloro-4-pyridyl)- $\mathrm{N}^{2}$-phenylurea) and copper in excess. We found that endogenous polyamines, and mainly the conjugated fraction, are involved in the cell division processes of isolated zucchini cotyledons and their changes are related to the specific action of the used growth regulating factors.
\end{abstract}

\section{Keywords}

Cell Division, Cotyledons, Cytokinins, Heavy Metal, Polyamines

\section{Introduction}

Polyamines (PAs) are nitrogen-containing organic molecules, widely distributed in both higher and lower plants, and the PAs common to all plant species are putrescine (Put), spermidine (Spd) and spermine (Spm). They occur as free molecules, but can also be conjugated with small molecules (phenolic acids) or bound to macromolecules like nucleic acids and proteins [1]. Although the conjugation of polyamines is discussed as a regulatory mechanism of the free PAs pool, conjugated PAs are also implicated in a variety of stress-induced plant responses and developmental processes [2]. PAs are involved in normal growth and development of plants and play significant roles in a range of developmental and physiological processes such as regulation of gene expression,

\footnotetext{
"Corresponding author.
}

How to cite this paper: Damyanova, M., Todorova, D. and Sergiev, I. (2014) Polyamine Alterations in Isolated Zucchini Cotyledons Grown in Presence of Cytokinins and $\mathrm{Cu}^{2+}$. American Journal of Plant Sciences, 5, 2141-2147. 
translation, cell proliferation and cell death (particularly apoptosis), somatic embryogenesis, differentiation and morphogenesis, dormancy breaking of tubers and in seed germination, development and senescence of flowers, leaves and fruits (reviewed by [3] [4]).

Cytokinins (CKs) are important phytohormones which play a key role in several aspects of plant growth, metabolism and development at normal growth conditions. For example CKs are the main phytohormones responsible for cotyledon growth and development [5]-[8]. A number of articles documented the alterations of PAs quantity provoked by treatment of plants (or cotyledons) with exogenous CKs [9]-[18]. Generally the PAs are accumulated after CK application and these changes depend on plant organs and species and CK concentrations applied.

Copper $(\mathrm{Cu})$ is a micronutrient which plays an important role in various physiological processes as photosynthesis, respiration, chlorophyll synthesis, cell wall metabolism, antioxidant activity, etc. [19] [20]. However in excess, it causes strong phytotoxic and oxidative damages [19] and inhibits cell division [21]. Several articles documented the changes in PA plant metabolism due to Cu excess in nutrient solutions. Groppa et al. [22]-[24] found that PA metabolism was differently affected in sunflower and wheat leaf discs treated with $\mathrm{Cu}$. Put content increased significantly in both plants after $\mathrm{Cu}$ treatments, Spd was not modified by $\mathrm{Cu}$, while Spm was increased in sunflower, but it was reduced in wheat as compared to the respective controls [22] [23]. Additionally, the authors suggested that PAs are key biological compounds, probably involved in signaling pathways which are triggered under heavy metal stress conditions [24]. Szafranska et al. [25] examined the effect of $\mathrm{Cu}$ on the regeneration of Daucus carota L. androgenic embryos of var. Feria and 1014 breeding line as well as on PAs content and found that the variations in PA levels depend not only on the concentrations of heavy metal, but also on plant species and cultivars.

Here we examine the possible role of polyamines in the growth of Cucurbita pepo cotyledons incubated on cytokinins (4PU-30, BA) and $\mathrm{Cu}$ in a presence of light.

\section{Materials and Methods}

\subsection{Plant Material and Growth Conditions}

Seeds of Cucurbita pepo L., cv. Cocozelle var. Tripolis (zucchini) were stripped of their seed coats, and cotyledons isolated from the embryonic axes of the seed were placed in covered Petri dishes on filter paper soaked with distilled water (control) or with water supplemented with either $\mathrm{CuSO}_{4}(500 \mu \mathrm{M}), 10 \mu \mathrm{M}$ BA $\left(\mathrm{N}^{6}\right.$-benzylaminopurine), $10 \mu \mathrm{M} 4 \mathrm{PU}-30$; and combinations of them. We used this high concentration of $\mathrm{Cu}$ in order to obtain evident inhibition of growth. The cotyledons were allowed to develop under continuous light (150 $\mu \mathrm{mol} \cdot \mathrm{m}^{-2} \cdot \mathrm{s}^{-1}$ ) at temperature $28^{\circ} \mathrm{C}$. The analyses were performed on 6-day-old cotyledons when any cell division processes were finished [26]. The following CKs were tested: purine type BA ( $\mathrm{N}^{6}$-benzylaminopurine) from Sigma-Aldrich, and phenylurea type 4PU-30 ( $\mathrm{N}^{1}$-(2-chloro-4-pyridyl)- $\mathrm{N}^{2}$-phenylurea) kindly provided by Prof. Koichi Shudo (University of Tokyo, Japan).

\subsection{Polyamine Extraction and Determination}

Cotyledons (approximately $200 \mathrm{mg}$ ) were ground in mortar with pestle in $2 \mathrm{ml}$ of trichloroacetic acid (TCA). After centrifugation (30 min, 15,000 ×g) the supernatant and pellet were used for further analyses.

The direct dansylation method was used to determine the free Put, Spd and Spm levels [27]. Conjugated PAs were measured in acid-hydrolyzed supernatants as TCA-soluble bound PAs, and bound PAs in acid-hydrolyzed pellets as TCA-insoluble bound polyamines, according to [28]. The three fractions of PAs were separated using TLC precoated plates of Silicagel G 60 (Merck) in a cyclohexane:ethylacetate (3:2, v/v) solvent system. Spots, visualised under UV light, were scraped off and eluted in $2 \mathrm{ml}$ anhydrous acetone. Fluorescence was measured (excitation $360 \mathrm{~nm}$, emission $505.5 \mathrm{~nm}$ ) and the results were compared with dansylated PA standards loaded on the same TLC plate and treated as extracted samples.

\subsection{Statistical Procedures}

All experiments were repeated three times with three to five replications. The results reported in the figures are means of the values with standard error (SE). Data were statistically examined by Fisher's least significance difference (LSD). The different letters in figures indicate significant differences between treatments at $\alpha<0.05$. 


\section{Results}

Both CKs caused a significant increase of free Put (Figure 1(A)) which was more pronounced after 4PU-30 application-more than 3 times in comparison with the control value. Copper did not change the Put content when was applied alone, but it caused considerable reduction of free Put level when was added in combination with BA and especially with 4PU-30. In relation to conjugated Put (Figure 1(B)) both CKs caused a noticeable decrease of its content. The application of $\mathrm{Cu}$ increased this fraction as compared to the relative levels of control and CK-treated variants. Bound Put fraction (Figure 1(C)) was altered in the same manner as conjugated Put with exception of the alone applied BA, which increased by 52\% the insoluble conjugated Put.

There were no significant changes in free Spd content (Figure 2(A)) after treatment with $\mathrm{Cu}$-alone or in combination with CKs. Benzyl adenine decreased free Spd by 43\%, and 4PU-30 augmented free Spd by $46 \%$. Conjugated Spd (Figure 2(B)) was increased almost twice after application of Cu alone or Cu + BA. The other treatments did not affect this fraction of Spd. Bound Spd (Figure 2(C)) content was augmented by both CK treatments. The presence of $\mathrm{Cu}$ in the medium increased Spd levels and the effect of $\mathrm{Cu}+\mathrm{BA}$ combination was most pronounced-up to $51 \%$ as compared to the alone BA application.

The free Spm level increased to $129 \%$ by 4PU-30 (Figure 3(A)), and there were no significant alterations after application of purine CK or heavy metal. However in combination with both types of CKs the Cu caused the increase of this fraction by $60 \%$ as compared to $\mathrm{Cu}$ applied alone. Both CKs provoked considerable decrease in

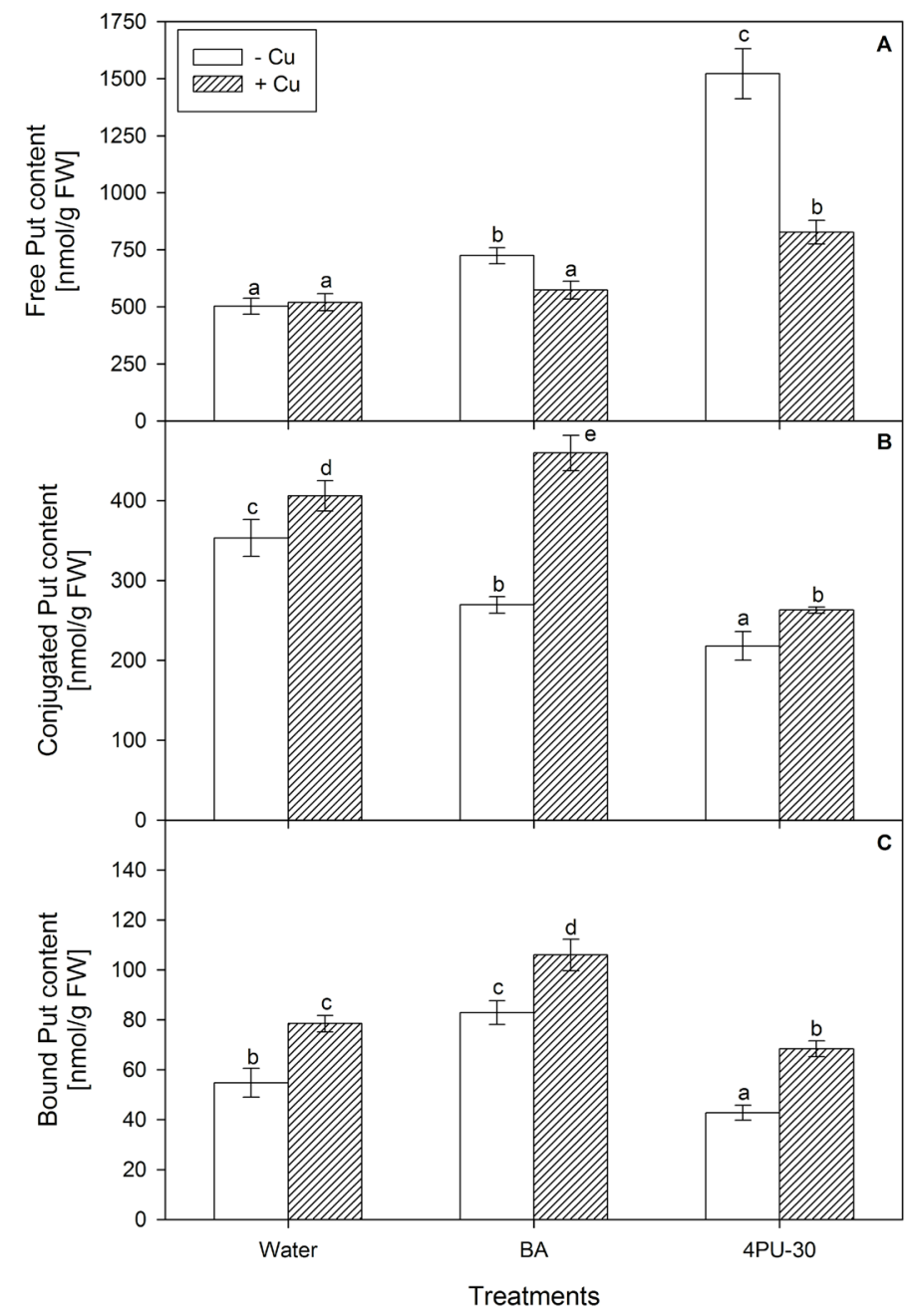

Figure 1. Content of putrescine free (A), conjugated (B) and bound (C) in zucchini cotyledons incubated on solutions of cytokinins and copper (mean values $\pm \mathrm{SE}$ ). 


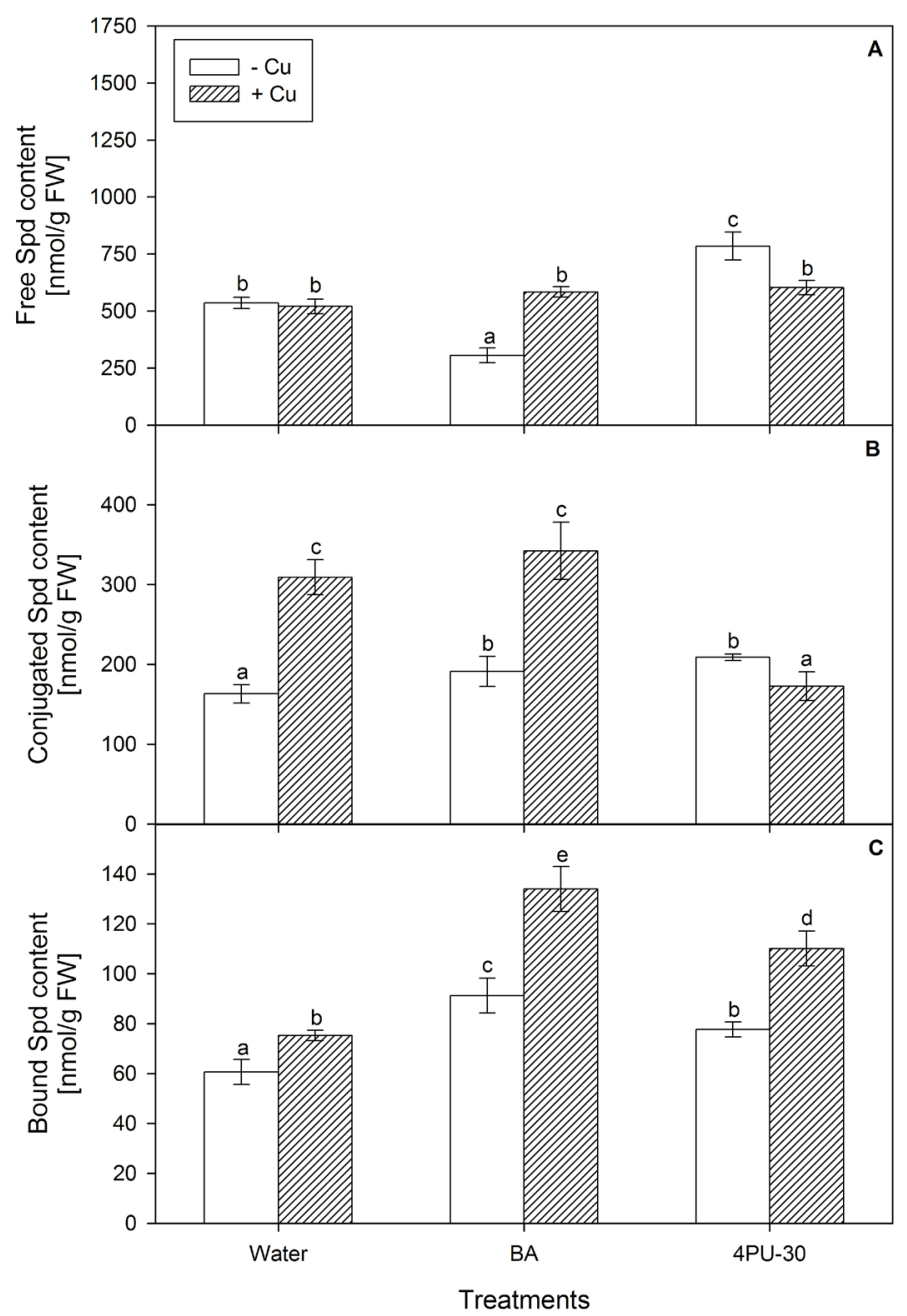

Figure 2. Content of spermidine free (A), conjugated (B) and bound (C) in zucchini cotyledons incubated on solutions of cytokinins and copper (mean values $\pm \mathrm{SE}$ ).

conjugated Spm (Figure 3(B)) — up to 16\% by BA treatment and more than $68 \%$ by 4 PU-30. Application of Cu alone or in combination with BA decreased this Spm fraction by 22\% and 30\% respectively. Only traces of conjugated Spm were detected after the treatment with combination of phenylurea CK and heavy metal. Bound Spm (Figure 3(C)) also was decreased by the application of CKs-by 24\% (BA) and 51\% (4PU-30) respectively. There were no significant alterations in this fraction neither by the single heavy metal nor by the combination with CKs.

In general, all treatments increased the total polyamine content (Table 1) with exception of BA, which decreased the total amount of Spd and Spm, while 4PU-30 increased all polyamines. The heavy metal also enhanced the polyamine titers but in a lesser degree than the phenylurea cytokinin.

\section{Discussion}

Polyamines are involved in a variety of major developmental processes. In our research we focused on the role of PAs at the end of cell proliferation of zucchini cotyledons. On day 6 all cell division processes are finished and further growth of cotyledons incubated on water is mainly due to cell enlargement [26]. At this stage cotyledons grown on CKs finished their cell division 2 - 3 days earlier and these grown on $\mathrm{Cu}$ still attempted to divide. The role of cytokinins in plant cell proliferation is well known [29]. On the other hand $\mathrm{Cu}$ induces inhibitory effects on zucchini cell proliferation [30]. We found that conjugated PAs decreased (or little altered in case 


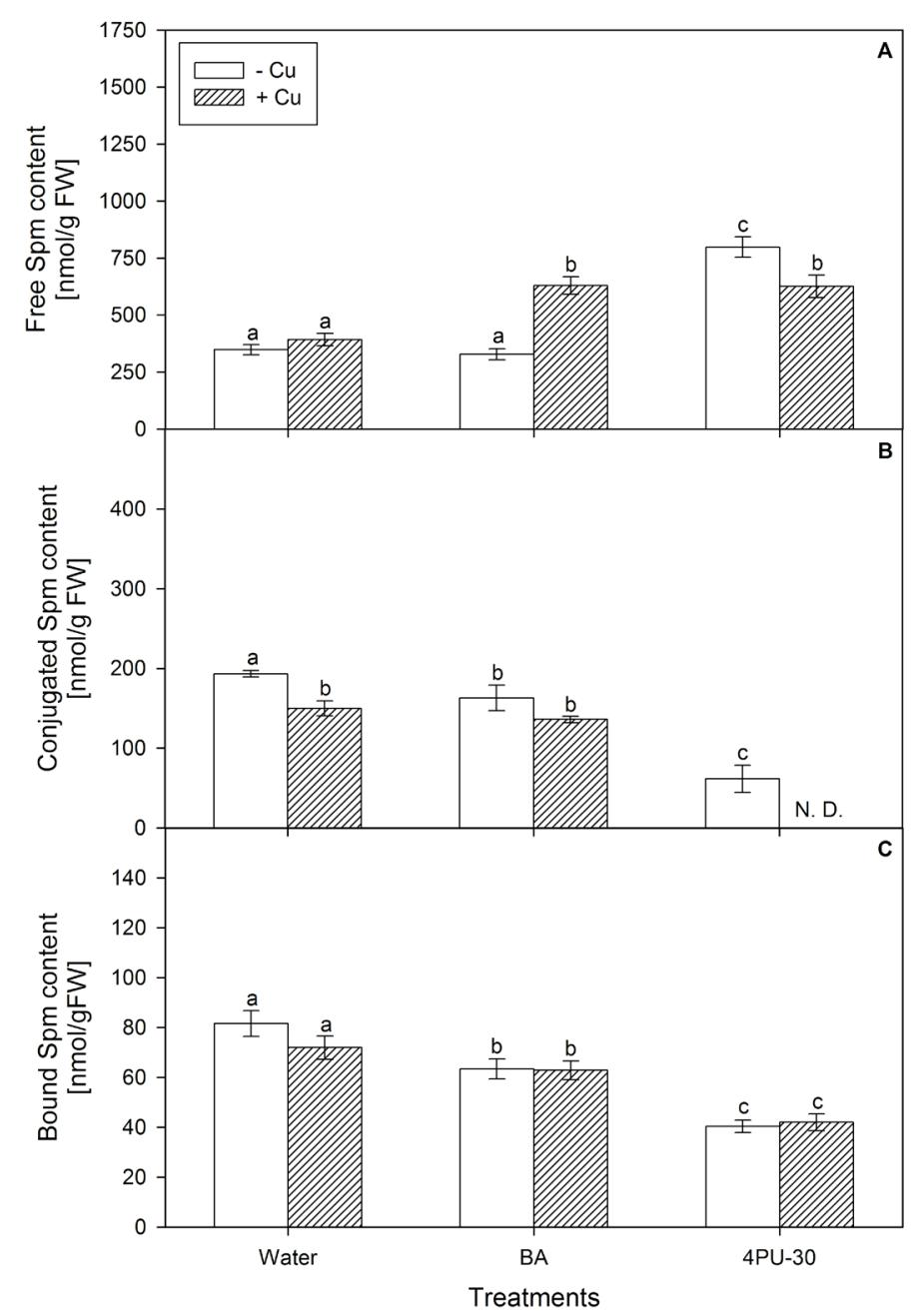

Figure 3. Content of spermine free (A); conjugated (B) and bound (C) in zucchini cotyledons incubated on solutions of cytokinins and copper (mean values $\pm \mathrm{SE}$ ).

Table 1. Total polyamine content (nmol/g FW) in zucchini cotyledons incubated on solutions of cytokinins and copper. Values are calculated on the basis of the data presented in Figures 1-3.

\begin{tabular}{ccccccc}
\hline & Control & BA & 4 PU-30 & $\mathrm{Cu}$ & $\mathrm{Cu}+\mathrm{BA}$ & $\mathrm{Cu}+4 \mathrm{PU}-30$ \\
\hline Total Put & 910.3 & 1076.0 & 1782.4 & 1003.8 & 1139.2 & 1158.6 \\
Total Spd & 759.8 & 587.8 & 1071.5 & 904.4 & 1059.9 & 885.8 \\
Total Spm & 623.0 & 544.2 & 899.6 & 613.8 & 828.4 & 668.6 \\
Put + Spd + Spm & 2293.1 & 2218.0 & 3753.5 & 2522.0 & 3027.5 & 2713.0 \\
\hline
\end{tabular}

of Spd) in cotyledons incubated on CK solutions, probably because the zucchini cells do not need to maintain high levels of this PA fraction since on day 6 the division processes are finished. Furthermore, the free PAs pool raise could be a result of the conversion of conjugated PAs into free forms. However, significantly increased free PAs in cotyledons treated with 4PU-30 (more than it could be expected if they were converted from the relevant conjugated forms) suggested that de novo synthesis of PAs is involved. These results are relevant to previous findings which showed that 4PU-30 provoked a strong accumulation of PAs [11] [15]-[18]. Conjugated polyamine levels are found to be high in proliferating tissues of tobacco and tomato ovaries, and tobacco and citrus 
flowers as well dividing protoplasts of Vigna aconitifolia as reviewed by Egea-Cortines and Mizrahi [31]. We found that conjugated Put and Spd are also accumulated in cotyledons incubated on Cu probably to compensate the cell proliferation inhibited by heavy metal. On the other hand in combination with BA the heavy metal provoked a higher amount of PAs in comparison with the other combination. Probably an abundance of PAs was necessary to maintain the normal cell proliferation in this variant. Moreover, Stoynova-Bakalova and Petrov [30] showed that BA was less effective in cell division than 4PU-30 when combined with $\mathrm{Cu}$. The authors evidenced that BA did not succeed to restore Cu-suppressed cotyledon cell division and even enhanced the inhibitory effect of the heavy metal. In this case the accumulation of PAs was necessary to "strengthen" the CK action in view of the fact that according to Galston [32] PAs are described as "second messengers" of CK action. On the other hand 4PU-30 definitely counteracted the Cu-caused inhibition of cell proliferation [30]. So the lesser accumulation of PAs in the cotyledons simultaneously treated with 4PU-30 and $\mathrm{Cu}$ as well as the "disappearance" of the conjugated Spm fraction are supplementary evidence that 4PU-30 overcame the inhibitory effect of $\mathrm{Cu}$.

\section{Conclusion}

Our data concerning the alterations of plant PA titers after treatment with exogenous cytokinins—alone or in combination with heavy metal complemented the existing knowledge of PAs interactions with other plant growth regulation substances. This investigation presents new information regarding the role of PAs in cell proliferation of zucchini cotyledons incubated on solution of cytokinins and $\mathrm{Cu}$. The results prove that endogenous PAs (and mainly the conjugated fraction) are involved in the cell division processes and their alterations are directly related to specific action of the tested growth regulating factors.

\section{Acknowledgements}

This work was supported by the grant No. BG051PO001-3.3.06-0025, financed by the European Social Fund and Operational Programme Human Resources Development (2007-2013) and co-financed by Bulgarian Ministry of Education and Science.

\section{References}

[1] Groppa, M.D. and Benavides, M.P. (2008) Polyamines and Abiotic Stress: Recent Advances. Amino Acids, 1, 35-45. http://dx.doi.org/10.1007/s00726-007-0501-8

[2] Bouchereau, A., Aziz, A., Larher, F. and Martin-Tanguy, J. (1999) Polyamines and Environmental Challenges: Recent Development. Plant Science, 140, 103-125. http://dx.doi.org/10.1016/S0168-9452(98)00218-0

[3] Kusano, T., Berberich, T., Tateda, C. and Takahashi, Y. (2008) Polyamines: Essential Factors for Growth and Survival. Planta, 228, 367-381. http://dx.doi.org/10.1007/s00425-008-0772-7

[4] Wimalasekera, R., Tebartz, F. and Scherer, G.F.E. (2011) Polyamines, Polyamine Oxidases and Nitric Oxide in Development, Abiotic and Biotic Stresses. Plant Science, 181, 593-603. http://dx.doi.org/10.1016/j.plantsci.2011.04.002

[5] Stoynova-Bakalova, E., Karanov, E., Petrov, P. and Hall, M.A. (2004) Cell Division and Cell Expansion in Cotyledons of Arabidopsis Seedlings. New Phytologist, 162, 471-479. http://dx.doi.org/10.1111/j.1469-8137.2004.01031.x

[6] Stoynova-Bakalova, E., Petrov, P.I., Gigova, L. and Baskin, T.I. (2008) Differential Effects of Methyl Jasmonate on Growth and Division of Etiolated Zucchini Cotyledons. Plant Biology, 10, 476-484. http://dx.doi.org/10.1111/j.1438-8677.2008.00034.x

[7] Stoynova-Bakalova, E. and Petrov, P. (2006) Control by Cytokinins of the Cellular Behaviour in the Plate Meristem of Zucchini Cotyledons. Planta, 223, 1256-1262. http://dx.doi.org/10.1007/s00425-005-0173-0

[8] Stoynova-Bakalova, E. and Petrov, P.I. (2009) Modulating Zucchini Cotyledon Plate Meristem Activity by Interactions between the Cycline-Dependent Kinase Inhibitor Roscovitine and Cytokinins. Plant Cell Tissue and Organ Culture: Journal of Plant Biotechnology, 98, 1-7.

[9] Cho, S.-C. (1983) Effects of Cytokinin and Several Inorganic Cations on the Polyamine Content of Lettuce Cotyledons. Plant and Cell Physiology, 24, 27-32.

[10] Walker, M.A., Roberts, D.R. and Dumbroff, E.B. (1988) Effect of Cytokinin and Light on Polyamines during the Greening Response of Cucumber Cotyledons. Plant and Cell Physiology, 29, 201-205.

[11] Sergiev, I., Alexieva, V. and Karanov, E. (1995) Cytokinin and Anticytokinin Effects on Growth and Free Polyamine Content in Etiolated and Green Radish Cotyledons. Journal of Plant Physiology, 145, 266-270. http://dx.doi.org/10.1016/S0176-1617(11)81888-2 
[12] Legocka, J. and Żarnowska, A. (1999) Role of Polyamines in the Cytokinin-Dependent Physiological Processes. I. Effect of Benzyladenine on Polyamine Levels during Chloroplast Differentiation in the Tissue Culture of Dianthus caryophyllus. Acta Physiologiae Plantarum, 21, 349-354. http://dx.doi.org/10.1007/s11738-999-0006-z

[13] Legocka, J. and Żarnowska, A. (2000) Role of Polyamines in the Cytokinin-Dependent Physiological Processes II. Modulation of Polyamine Levels during Cytokinin-Stimulated Expansion of Cucumber Cotyledons. Acta Physiologiae Plantarum, 22, 395-401. http://dx.doi.org/10.1007/s11738-000-0079-1

[14] Todorova, D. and Alexieva, V. (2002) Changes in Polyamine Content in Wild Type Arabidopsis thaliana Plants Treated with Ethrel, BA and CPPU Separately and in Combinations. Comptes rendus de l'Academie bulgare des Sciences, 55, 85-90.

[15] Todorova, D., Alexieva, V. and Karanov, E. (2002) Effect of Some Cytokinins and Their Combination with Ethrel on the Endogenous Polyamine Content in Ethylene Insensitive Mutant eti5 Type of Arabidopsis thaliana (L.) Heynh Plants. Comptes rendus de l'Academie bulgare des Sciences, 55, 89-94.

[16] Todorova, D., Sergiev, I., Kornova, K., Alexieva, V. and Karanov, E. (2005) Effect of Some Plant Growth Regulators on Physiological and Biochemical Status of in Vitro Microprapagated Plantlets from Apples during Adaptation. Comptes rendus de l'Academie bulgare des Sciences, 58, 953-956.

[17] Todorova, D., Kapchina-Toteva, V., Yakimova, E., Sergiev, I., Alexieva, V. and Karanov, E. (2005) Effects of Some Plant Growth Regulators on the Endogenous Polyamine Content in in Vitro Cultivated Rosa hybrida L., cv. Madelon. Comptes rendus de l'Academie bulgare des Sciences, 58, 433-438.

[18] Todorova, D., Moskova, I., Sergiev, I., Alexieva, V. and Mapelli, S. (2008) Changes in Endogenous Polyamines and Some Stress Markers Content Induced by Drought, 4PU-30 and Abscisic Acid in Wheat Plants. In: Khan, N. and Singh, S., Eds., Abiotic Stress and Plant Responses, I.K. International Publishing House Pvt. Ltd, New Delhi, 205-215.

[19] Yadav, S.K. (2010) Heavy Metals Toxicity in Plants: An Overview on the Role of Glutathione and Phytochelatins in Heavy Metal Stress Tolerance of Plants. South African Journal of Botany, 76, 167-179. http://dx.doi.org/10.1016/j.sajb.2009.10.007

[20] Hänsch, R. and Mendel, R.R. (2009) Physiological Functions of Mineral Micronutrients (Cu, Zn, Mn, Fe, Ni, Mo, B, Cl). Current Opinion in Plant Biology, 12, 259-266. http://dx.doi.org/10.1016/j.pbi.2009.05.006

[21] Jiang, W., Liu, D. and Liu, X. (2001) Effects of Copper on Root Growth, Cell Division, and Nucleolus of Zea mays. Biologia Plantarum, 44, 105-109. http://dx.doi.org/10.1023/A:1017982607493

[22] Groppa, M.D., Tomaro, M.L. and Benavides, M.P. (2007) Polyamines and Heavy Metal Stress: The Antioxidant Behavior of Spermine in Cadmium- and Copper-Treated Wheat Leaves. Biometals, 20, 185-195. http://dx.doi.org/10.1007/s10534-006-9026-y

[23] Groppa, M.D., Ianuzzo, M.P., Tomaro, M.L. and Benavides, M.P. (2007) Polyamine Metabolism in Sunflower Plants under Long-Term Cadmium or Copper Stress. Amino Acids, 32, 265-275. http://dx.doi.org/10.1007/s00726-006-0343-9

[24] Groppa, M.D., Zawoznik, M.S., Tomaro, M.L. and Benavides, M.P. (2008) Inhibition of Root Growth and Polyamine Metabolism in Sunflower (Helianthus annuus) Seedlings under Cadmium and Copper Stress. Biological Trace Element Research, 126, 246-256. http://dx.doi.org/10.1007/s12011-008-8191-y

[25] Szafranska, K., Cvikrova, M., Kowalska, U., Gorecka, K., Gorecki, R., Martincova, O. and Janas, K.M. (2011) Influence of Copper Ions on Growth, Lipid Peroxidation, and Proline and Polyamines Content in Carrot Rosettes Obtained from Anther Culture. Acta Physiologiae Plantarum, 33, 851-859. http://dx.doi.org/10.1007/s11738-010-0610-y

[26] Stoynova-Bakalova, E. (2007) Properties of Plate Meristem of Growing Epigeal Cotyledons in an Experimental System. Environmental and Experimental Botany, 59, 76-83. http://dx.doi.org/10.1016/j.envexpbot.2005.10.010

[27] Smith, T. and Best, G. (1977) Polyamines in Barley Seedlings. Phytochemistry, 16, 841-843. http://dx.doi.org/10.1016/S0031-9422(00)86676-5

[28] Torrigiani, P., Altamura, M., Copitani, F., Serafini-Fracasini, D. and Bagni, N. (1989) De Novo Root Formation in Thin Cell Layers of Tobacco: Changes in Free and Bound Polyamines. Physiologia Plantarum, 77, $294-301$. http://dx.doi.org/10.1111/j.1399-3054.1989.tb05644.x

[29] Letham, D. (1971) Regulators of Cell Division in Plant Tissues. XII. A Cytokinin Bioassay Using Excised Radish Cotyledons. Physiologia Plantarum, 25, 391-396. http://dx.doi.org/10.1111/j.1399-3054.1971.tb01462.x

[30] Stoynova-Bakalova, E. and Petrov, P. (2010) Effects of Chemically Differing Cytokinins on Zucchini Cotyledon Growth in Presence of Copper in Excess. Comptes rendus de l'Academie bulgare des Sciences, 63, 249-256.

[31] Egea-Cortines, M. and Mizrahi, Y. (1991) Polyamines in Cell Division, Fruit Set and Development, and Seed Germination. In: Slocum, R. and Flores, H., Eds., Biochemistry and Physiology of Polyamines in Plants, CRC Press, 143-158.

[32] Galston, A. (1983) Polyamines as Modulators of Plant Development. Bioscience, 33, 382-388. http://dx.doi.org/10.2307/1309107 
Scientific Research Publishing (SCIRP) is one of the largest Open Access journal publishers. It is currently publishing more than 200 open access, online, peer-reviewed journals covering a wide range of academic disciplines. SCIRP serves the worldwide academic communities and contributes to the progress and application of science with its publication.

Other selected journals from SCIRP are listed as below. Submit your manuscript to us via either submit@scirp.org or Online Submission Portal.
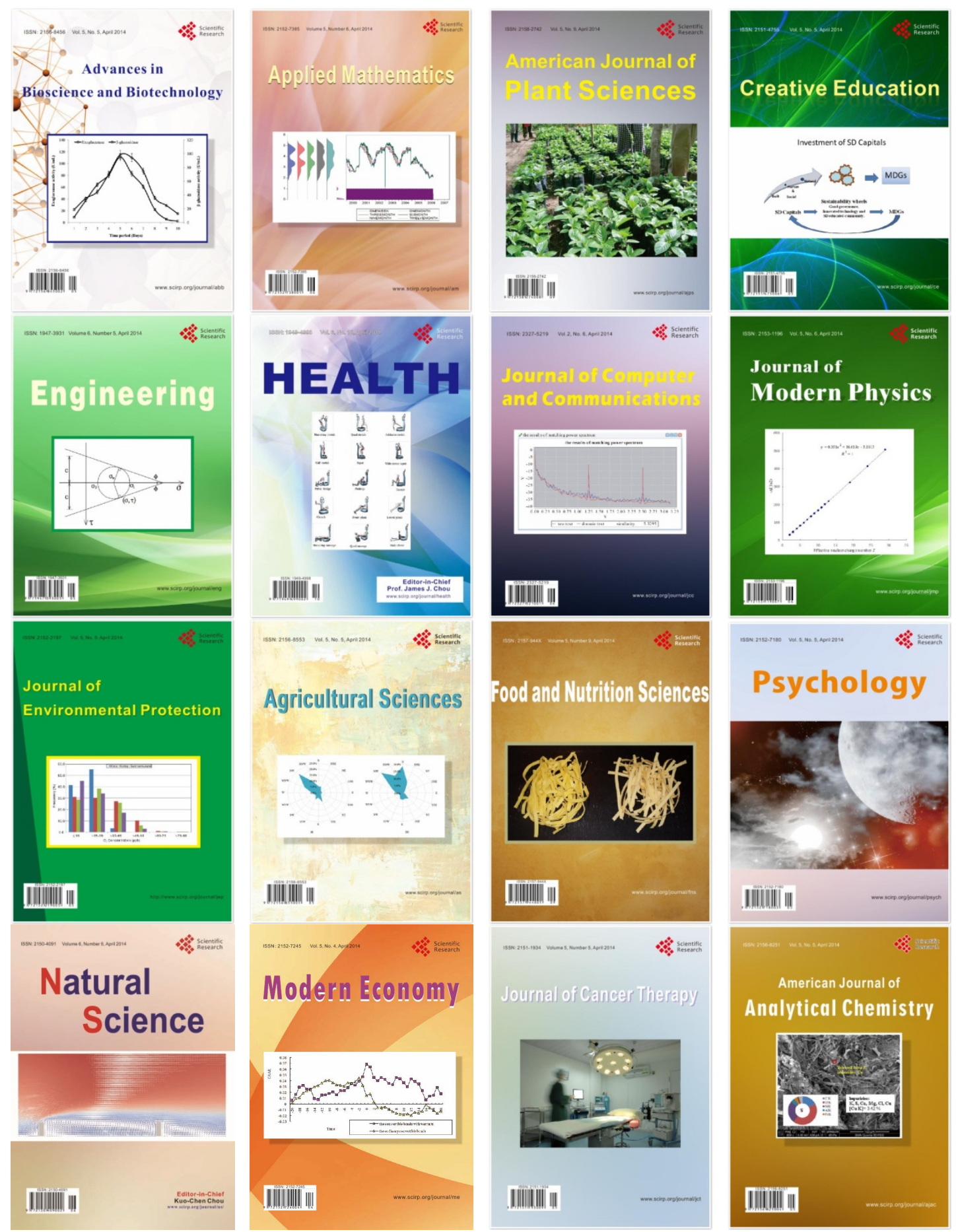